\title{
The association between the time from oxytocin cessation during labour to Cesarean delivery and postpartum blood loss: a retrospective cohort study
}

\section{L'association entre l'intervalle de temps allant de l'interruption de l'ocytocine pendant le travail obstétrical à l'accouchement par césarienne et les pertes sanguines en postpartum: une étude de cohorte rétrospective}

\author{
Gary Tran, MSc $\cdot$ Marcelo Kanczuk, MD $\cdot$ Mrinalini Balki, MBBS, MD \\ Received: 29 November 2016/Revised: 9 February 2017/Accepted: 10 April 2017/Published online: 18 April 2017 \\ (C) Canadian Anesthesiologists' Society 2017
}

\begin{abstract}
Purpose Prolonged exposure to oxytocin during augmentation of labour is associated with uterine atony and an increased risk of postpartum hemorrhage (PPH) due to oxytocin receptor desensitization. Cessation of oxytocin infusion during labour may facilitate recovery of oxytocin receptor function, which then helps to restore myometrial contractility and decrease postpartum blood loss. We examined the association between oxytocin recovery interval, i.e., the time from discontinuing oxytocin to Cesarean delivery (CD) for labour arrest, and blood loss.

Methods This retrospective cohort study included women who underwent $C D$ for labour arrest following oxytocinaugmented labour from July 1, 2013 to July 19, 2015 at our institution. Data were collected on patient demographics, labour and delivery characteristics, oxytocin induction and
\end{abstract}

This paper was presented in part at the 48th Annual Society for Obstetric Anesthesia and Perinatology (SOAP) Meeting, Boston, Massachusetts, United States, May 18-22, 2016.

G. Tran, MSc

Faculty of Medicine, Mount Sinai Hospital, University of

Toronto, Toronto, ON, Canada

M. Kanczuk, MD · M. Balki, MBBS, MD ( $\square)$

Department of Anesthesia and Pain Management, Mount Sinai

Hospital, University of Toronto, 600 University Avenue,

Toronto, ON M5G 1X5, Canada

e-mail: Mrinalini.balki@uhn.ca

M. Balki, MBBS, MD

Department of Obstetrics and Gynaecology, Mount Sinai

Hospital, University of Toronto, Toronto, ON, Canada augmentation, recovery interval, and PPH risk factors. The primary outcome was estimated blood loss (EBL), calculated using the hematocrit variation method.

Results Data on 490 women were analyzed. The mean (standard deviation) EBL was 1,341 (577) $\mathrm{mL}$; the amount of oxytocin administered during labour was $6,447(6,868)$ $m U$, and the oxytocin recovery interval was 99 (65) min. Every ten-minute increase in the recovery interval was associated with a 10-mL decrease in EBL (95\% confidence interval [CI], -18 to $-3 ; P=0.009$ ). Morbidly obese women had a significantly higher EBL than those with a body mass index $<40 \mathrm{~kg} \cdot \mathrm{m}^{-2}$ (mean difference, $572 \mathrm{~mL}$; 95\% CI, 382 to 762; $P<0.001)$. The amount and duration of oxytocin administered during labour, but not the oxytocin recovery interval, was associated with the use of additional interventions to control PPH $(P=0.005)$.

Conclusion Our study shows that an increase in the oxytocin recovery interval is associated with a decrease in blood loss at CD in women with oxytocin augmented labour. These data support discontinuing the oxytocin infusion as soon as the decision is made to proceed with CD for labour arrest, particularly in morbidly obese women.

\footnotetext{
Résumé

Objectif Une exposition prolongée à l'ocytocine pendant l'augmentation du travail obstétrical est associée à une atonie utérine et à un risque accru d'hémorragie postpartum (HPP) en raison de la désensibilisation des récepteurs à l'ocytocine. L'interruption de la perfusion d'ocytocine pendant le travail pourrait faciliter la récupération de la fonction des récepteurs de l'ocytocine,
} 
ce qui faciliterait alors le rétablissement de la contractilité myométriale et réduirait les pertes sanguines en postpartum. Nous avons examiné l'association entre l'intervalle de récupération de l'ocytocine, soit l'intervalle de temps entre l'interruption de l'ocytocine et l'accouchement par césarienne (AC) pour l'arrêt du travail obstétrical, et les pertes sanguines.

Méthode Cette étude de cohorte rétrospective a inclus des femmes ayant subi un AC dans notre institution en raison de l'arrêt du travail obstétrical suite à l'accélération du travail obstétrical par ocytocine entre le $1^{\text {er }}$ juillet 2013 et le 19 juillet 2015. Les données suivantes ont été colligées : renseignements démographiques des patientes, caractéristiques du travail obstétrical et de l'accouchement, induction à l'ocytocine et augmentation de la dose, intervalle de récupération et facteurs de risque d'HPP. Le critère d'évaluation principal était la perte sanguine estimée (PSE), calculée selon la méthode de variation de l'hématocrite.

Résultats Les données de 490 femmes ont été analysées. La PSE moyenne (écart type) était de 1341 (577) mL; la quantité d'ocytocine administrée pendant le travail était de 6447 (6868) $\mathrm{mU}$, et l'intervalle de récupération de l'ocytocine de 99 (65) min. Chaque augmentation de dix minutes de l'intervalle de récupération a été associée à une réduction de $10 \mathrm{~mL}$ de la PSE (intervalle de confiance [IC] $95 \%,-18$ à $-3 ; P=0,009)$. Les femmes obèses morbides avaient une PSE significativement plus élevée que celles ayant un indice de masse corporel $<40 \mathrm{~kg} \cdot \mathrm{m}^{-2}$ (différence moyenne, 572 mL; IC $95 \%$, 382 à 762; P<0,001). La quantité d'ocytocine et la durée d'administration pendant le travail, mais non l'intervalle de récupération de l'ocytocine, étaient associées au recours à des interventions supplémentaires pour maîtriser l'HPP $(P=0,005)$.

Conclusion Notre étude montre qu'une prolongation de l'intervalle de récupération de l'ocytocine est associée à une réduction des pertes sanguines lors d'un AC chez des femmes ayant reçu de l'ocytocine pour soutenir leur travail obstétrical. Ces données appuient l'interruption de la perfusion d'ocytocine dès que l'on prend la décision de procéder à un AC pour cesser le travail, particulièrement chez les femmes obèses morbides.

Postpartum hemorrhage (PPH) is a leading cause of maternal morbidity and mortality worldwide. Its incidence has continued to rise in developed countries, including in Canada and the United States. ${ }^{1-3}$ The rise in PPH from 2003-2010 has been attributed largely to an increase in postpartum uterine atony despite the use of prophylactic agents such as oxytocin to improve uterine tone. 3,4

Oxytocin is a neurohypophyseal hormone that induces uterine contractions. It is the mainstay uterotonic drug for PPH prophylaxis and treatment as well as for labour induction and augmentation. 5,6 Use of prophylactic oxytocin during active management of the third stage of labour reduces the incidence of $\mathrm{PPH}$ by up to $60 \% .^{6,7}$ Conversely, the use of high-dose or prolonged infusions of oxytocin for labour augmentation is associated with an increased risk of PPH secondary to uterine atony., 8 Exposure of myometrial oxytocin receptors (OTRs) to oxytocin during labour augmentation results in receptor desensitization, which then reduces the responsiveness of OTRs to subsequent oxytocin administered for the prevention of primary PPH. ${ }^{10-13}$

There is some evidence in the literature suggesting resensitization of OTRs following cessation of oxytocin stimulation in a previously desensitized myometrium; however, this has not been consistently demonstrated in vitro. ${ }^{14-16}$ Moreover, in the clinical setting, it is unclear if discontinuing oxytocin after labour augmentation will allow for the myometrium to respond effectively to subsequent oxytocin stimulation.

The primary objective of our study was to assess the association between the oxytocin recovery interval (defined as the time from the cessation of oxytocin infusion during labour to delivery) and postpartum blood loss in women undergoing a Cesarean delivery (CD) for labour arrest after oxytocin-augmented labour. We hypothesized that an increase in the oxytocin recovery interval would reduce postpartum blood loss in these patients, possibly as a function of the recovery of myometrial OTRs.

\section{Methods}

Study design and population

After obtaining Research Ethics Board approval (REB 150181-C; August 10, 2015) at Mount Sinai Hospital (Toronto, Ontario, Canada), we conducted this retrospective chart review spanning July 1, 2013 to July 19, 2015. Patients who received oxytocin for labour augmentation and underwent CD for labour arrest under epidural anesthesia were identified by hospital Health Record Services. The charts were then screened to include patients with a gestational age of 37-41 weeks who received at least two hours of oxytocin infusion for labour augmentation. The two-hour threshold was based on prior studies indicating that this length of exposure induced OTR desensitization. ${ }^{10,14,15}$ Exclusion criteria included patients with PPH causes other than atony (such 
as genital tract or uterine trauma, coagulopathies and retained placental products), those with missing information on the outcome variables, or those who received general anesthesia. Both electronic and paper records were reviewed.

The data extracted from the charts included patient demographics, labour and delivery characteristics, oxytocin recovery interval, and known PPH risk factors ${ }^{8,9,16,17}$ (such as preeclampsia, chorioamnionitis, morbid obesity, macrosomia, multiple pregnancy, polyhydramnios, oxytocin induction, and oxytocin augmentation). The oxytocin protocol for labour augmentation at our institution consists of an initial rate of $2 \mathrm{mU} \cdot \mathrm{min}^{-1}$ and an increase of $2 \mathrm{mU} \cdot \mathrm{min}^{-1}$ approximately every $30 \mathrm{~min}$ as required to a maximum of $32 \mathrm{mU} \cdot \mathrm{min}^{-1}$. The attending nurses document the rate and timing of oxytocin administration in the electronic recording system in real time. The oxytocin infusion is typically stopped when the decision is made to proceed with $\mathrm{CD}$ after failure to progress in labour. Fluid administration during labour is standardized at the rate of $125 \mathrm{~mL} \cdot \mathrm{hr}^{-1} i v$ via infusion pump.

At our hospital, anesthesia for CD is normally achieved by a top-up via the epidural catheter using $2 \%$ lidocaine with 1:200,000 epinephrine along with fentanyl $50 \mu \mathrm{g}$ and epimorphine $2.5 \mathrm{mg}$. Immediately following delivery, all patients receive oxytocin as part of the active management of the third stage of labour for the prevention of PPH. Oxytocin $20 \mathrm{U} \cdot \mathrm{L}^{-1}$ is administered as an initial rapid infusion of 150-250 mL (i.e., 3-5 units), followed by 150 $\mathrm{mL} \cdot \mathrm{hr}^{-1}$ for approximately six hours. Patients with uterine atony are managed with additional bolus doses of oxytocin, or an increase in its concentration $\left(40 \mathrm{U} \cdot \mathrm{L}^{-1}\right)$, prior to receiving other uterotonic medications such as ergometrine, carboprost, and misoprostol.

\section{Study outcomes}

The primary outcome of the study was the amount of postpartum blood loss, expressed as the estimated blood loss (EBL). The EBL was determined using the hematocrit variation method, which assesses the change between the hematocrit level measured on admission and the level measured $24 \mathrm{hr}$ after the delivery (approximately $48 \mathrm{hr}$ apart) using the following formula: estimated blood volume $\mathrm{x}$ (preoperative hematocrit - postoperative hematocrit / preoperative hematocrit), where the estimated blood volume is the patient's weight $(\mathrm{kg})$ x 85 $\left(\mathrm{mL} \cdot \mathrm{kg}^{-1}\right){ }^{18-21}$

Additional interventions used to manage blood loss in the postpartum period were analyzed as the secondary outcomes. These interventions included administration of additional uterotonic drugs (bolus doses of oxytocin, ergometrine, and/or prostaglandins) or medications (tranexamic acid and calcium), transfusion of packed red blood cells (PRBCs) or other blood products, and surgical maneuvers (B-Lynch uterine compression sutures, ${ }^{22}$ uterine massage, Bakri balloon, ${ }^{23}$ hysterectomy, and uterine arterial clamping, ligation, and embolization).

Sample size estimation and statistical analysis

The sample size calculation was based on achieving a power of $80 \%$ and a global alpha of 0.05 for the multiple linear regression model. For each independent predictor variable in the regression model, it is recommended to have an absolute minimum of ten or up to 30 participants per predictor to ensure better power for detecting small differences. ${ }^{24}$ With nine independent variables in the regression model for this study, the selected sample size of 490 ensured that there was sufficient power for the study. The independent variables included in the analysis were: oxytocin recovery interval, preeclampsia, chorioamnionitis (confirmed by pathology), morbid obesity (body mass index [BMI] at delivery $\geq 40$ $\mathrm{kg} \cdot \mathrm{m}^{-2}$ ), macrosomia (birth weight $>4,500 \mathrm{~g}$ ), multiple gestation, polyhydramnios, oxytocin induction, and the dose/duration of oxytocin for augmentation.

A multiple linear regression analysis was performed to assess the association between the oxytocin recovery interval and EBL. A multiple logistic regression model assessed the association between oxytocin recovery interval and the secondary outcome (i.e., need for additional interventions to manage postpartum blood loss). The two statistical models incorporated potential risk factors for PPH as covariates to account for possible confounding variables. The covariates were tested for collinearity prior to building a regression model in order to prevent overadjustment of the data. Since we found a high correlation between the total dose and duration of oxytocin for labour augmentation, only the total amount of oxytocin infused was included in the statistical models. Data were presented as mean and (standard deviation [SD]), median with range or [interquartile range (IQR)], and frequencies, as appropriate. We used SAS ${ }^{\circledR}$ v9.3 (Cary, NC, USA) for the statistical analyses.

\section{Results}

The medical records of 490 women who received oxytocin for labour augmentation and underwent $\mathrm{CD}$ for labour arrest were reviewed. The process used to select the study population is described in Fig. 1. Patient demographics and labour and delivery characteristics are listed in Table 1 . Cesarean delivery was performed for failure of dilation in 


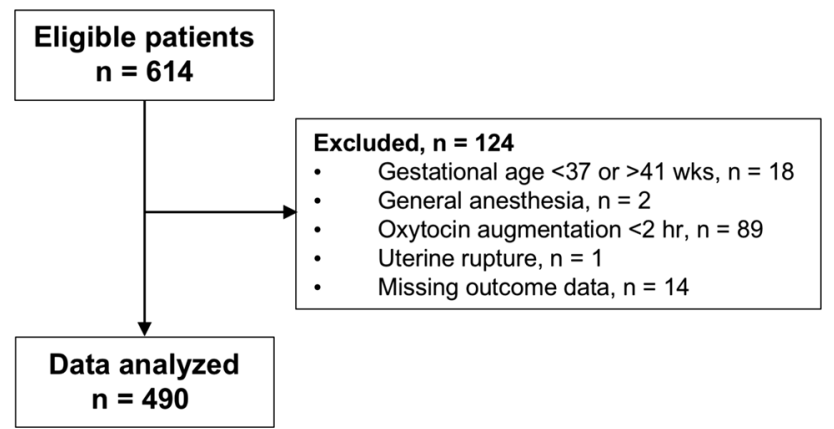

Fig. 1 Selection of the study population $(E B L=$ estimated blood loss)

Table 1 Demographics and labour and delivery characteristics of the study population

\begin{tabular}{ll}
\hline Characteristic & $n=490$ \\
\hline Age (yr), mean (SD) & $33.6(4.9)$ \\
Body mass index $\left(\mathrm{kg} \cdot \mathrm{m}^{-2}\right)$, mean (SD) & $31.3(5.9)$ \\
Primipara, $n(\%)$ & $433(88 \%)$ \\
Gestational age (weeks), mean (SD) & $39.6(1.3)$ \\
Patients with previous CD, $n(\%)$ & $25(5 \%)$ \\
Duration of epidural analgesia for labour (min), & $759(351)$ \\
$\quad$ mean (SD) & $309(63 \%)$ \\
Arrest of dilation, $n(\%)$ & $106(22 \%)$ \\
Arrest of descent, $n(\%)$ & $75(15 \%)$ \\
Arrest of dilation and descent, $n(\%)$ & $7(1-10)$ \\
Cervical dilation at CD, median (range) & $-2(-3-3)$ \\
Fetal station prior to CD, median (range) & $3,517(456)$ \\
Neonatal weight (g), mean (SD) &
\end{tabular}

$\mathrm{CD}=$ Cesarean delivery; $n=$ number of patients; $\mathrm{SD}=$ standard deviation

$309(63 \%)$ cases, failure of descent in $106(22 \%)$ cases, and failure of both dilation and descent in 75 (15\%) cases. Potential risk factors for PPH are shown in Table 2.

The mean (SD) oxytocin recovery interval was 99 (65) min, and the mean (SD) EBL in the study population was $1,341(577) \mathrm{mL}$. Eighty (16\%) patients required at least one additional intervention to manage their postpartum blood loss (Table 3). Of the $75(15 \%)$ patients receiving additional uterotonics or medications to manage uterine atony and blood loss, 17 received only additional oxytocin, whereas 43 patients received ergometrine, 28 received carboprost, 23 received misoprostol, and two received tranexamic acid. The remaining treatments, in descending order of frequency, were uterine massage, B-Lynch suture, transfusions of PRBCs or other blood products, and Bakri balloon (Table 3). None of the patients required a hysterectomy or uterine artery clamping, ligation, or embolization.
Table 2 Risk factors for postpartum hemorrhage $\mathrm{e}^{8,9,16,17}$

\begin{tabular}{ll}
\hline Risk factors present in the study population & $n(\%)$ or mean (SD) \\
\hline Morbid obesity & $30(6.1 \%)$ \\
Preeclampsia & $12(2.4 \%)$ \\
Chorioamnionitis & $41(8.4 \%)$ \\
Macrosomia & $10(2.0 \%)$ \\
Multiple pregnancy & $6(1.2 \%)$ \\
Polyhydramnios & $6(1.2 \%)$ \\
Oxytocin induction & $138(28.2 \%)$ \\
Oxytocin augmentation characteristics & \\
Total dose (mU) & $6,447(6,868)$ \\
Total duration of oxytocin exposure (min) & $619(355)$
\end{tabular}

$n(\%)=$ number $(\%)$ of patients with the risk factor; mean $(\mathrm{SD})=$ mean (standard deviation) of the oxytocin augmentation characteristics; Morbid obesity = body mass index $\geq 40 \mathrm{~kg} \cdot \mathrm{m}^{-2}$

Table 3 Clinical interventions to manage postpartum blood loss

\begin{tabular}{ll}
\hline Type of intervention & $n(\%)$ \\
\hline Additional uterotonics or medications* & $75(15.3)$ \\
Transfusion of blood or blood products & $6(1.2)$ \\
Uterine massage & $13(2.7)$ \\
B-Lynch suture & $6(1.2)$ \\
Bakri balloon & $1(0.2)$ \\
Uterine clamping, ligation or embolization & 0 \\
Hysterectomy & 0 \\
Total number of patients receiving at least one intervention & $80(16.3)$ \\
\hline$n(\%)=$ number $(\%)$ of patients with the intervention \\
*Additional oxytocin boluses, ergometrine, carboprost, misoprostol, \\
and tranexamic acid
\end{tabular}

After controlling for PPH risk factors, there was a significant inverse correlation between the oxytocin recovery interval and EBL (Fig. 2). Every ten-minute increase in the recovery period was associated with a 10 $\mathrm{mL}$ decrease in EBL (95\% CI, -18 to $-3 ; P=0.009$ ) (Table 4). Thus, in parturients waiting the average oxytocin recovery interval of $99 \mathrm{~min}$, the expected reduction in EBL would be $102 \mathrm{~mL}$. The mean (SD) EBL in women with a recovery interval $<$ one hour was higher than those with a recovery interval $\geq$ one hour [1,438 (586) $\mathrm{mL}$ vs 1,298 (569) $\mathrm{mL}$, respectively; mean difference, $140 \mathrm{~mL} ; 95 \% \mathrm{CI}, 29$ to $248 ; P=0.01]$. The length of the recovery period was not associated with the need for additional interventions to manage postpartum blood loss (odds ratio, 0.997; 95\% CI, 0.959 to 1.036; $P=0.87)$ (Table 4).

Approximately $210(43 \%)$ patients had one or more PPH risk factors. Except for morbid obesity, other risk factors were not found to have a notable effect on the amount of 


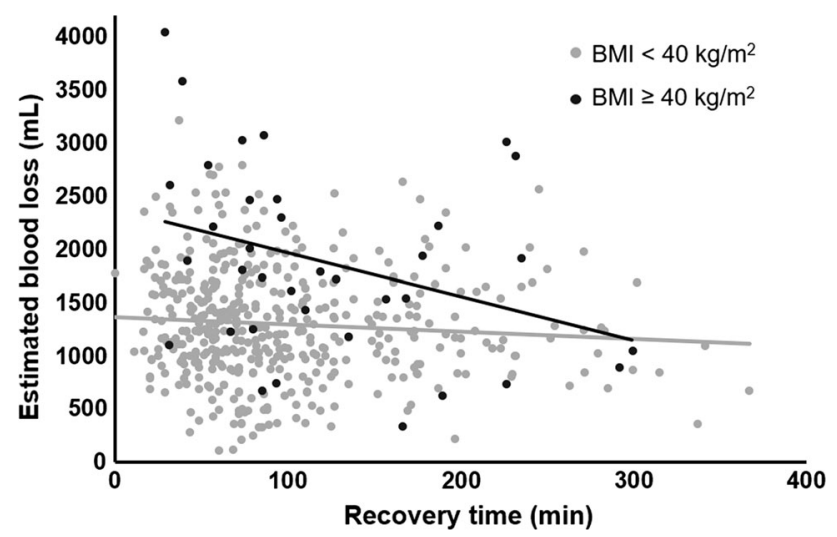

Fig. 2 Correlation between oxytocin recovery interval and estimated blood loss in patients undergoing Cesarean delivery for labour arrest. Line of best fit showing the correlation in women with body mass index $\geq 40 \mathrm{~kg} \cdot \mathrm{m}^{-2}$ (black line) and $<40 \mathrm{~kg} \cdot \mathrm{m}^{-2}$ (grey line)

EBL or on the need for additional interventions. Patients who were considered morbidly obese (i.e., BMI $\geq 40$ $\mathrm{kg} \cdot \mathrm{m}^{-2}$ ) had a significantly higher mean (SD) EBL than those with a BMI $<40 \mathrm{~kg} \cdot \mathrm{m}^{-2}[1,871(882) \mathrm{mL}$ vs 1,299 (525) $\mathrm{mL}$, respectively; mean difference, $572 \mathrm{~mL} ; 95 \% \mathrm{CI}$, 382 to $762 ; P<0.001]$. Nevertheless, morbid obesity was not associated with a significant increase in the need for additional interventions (odds ratio, $1.33 ; 95 \% \mathrm{CI}, 0.56$ to 3.2; $P=0.51)$.

We also tested an interaction between oxytocin recovery interval and EBL in morbidly obese women and found that an interaction exists between the two variables $(P$ value for the interaction $=0.004)$. The effect of the oxytocin recovery interval on EBL was found to be more profound in morbidly obese women than in non-obese women. For morbidly obese women, every ten-minute increase in the recovery period was associated with a $45-\mathrm{mL}$ decrease in EBL (95\% CI, -71 to $-20 ; P<0.001)$. For women with a BMI $<40 \mathrm{~kg} \cdot \mathrm{m}^{-2}$, although statistically not significant, the inverse association between the oxytocin recovery interval and EBL was still present; every ten-minute increase in the recovery period was associated with a $7-\mathrm{mL}$ decrease in EBL $(95 \% \mathrm{CI},-15$ to $1 ; P=0.10)$.

Oxytocin was used in $138(28 \%)$ patients to induce labour. All patients received oxytocin to augment labour. The mean (SD) duration and amount of oxytocin used for labour augmentation were 619 (355) min and 6,447 (6868) $\mathrm{mU}$, respectively. The maximum oxytocin infusion rate during labour augmentation was $13.9(7.9) \mathrm{mU} \cdot \mathrm{min}^{-1}$. Sixteen $(3.3 \%)$ women reached the maximum oxytocin infusion rate of $32 \mathrm{mU} \cdot \mathrm{min}^{-1}$ for a mean (SD) duration of 197 (237) min. Both the total amount and duration of oxytocin infusion during labour augmentation were associated with the need for additional interventions $(P \leq$ 0.01 ); however, they were not associated with an increase in EBL. For every 100-mU increase in the total amount of oxytocin infused, the odds of requiring additional interventions for control of bleeding increased by 1.004 (95\% CI, 1.001 to $1.008 ; P=0.005$ ). Since the amount and duration of oxytocin infusion were highly correlated (Spearman correlation coefficient $=0.92 ; P<0.001$ ), only the total amount of oxytocin infused was included in the two statistical models. The results were similar when the duration of oxytocin infusion was used for analysis.

Twenty-three (4.7\%) patients required additional interventions beyond uterotonics (blood transfusion, uterine massage, B-Lynch suture, and/or Bakri balloon). These patients had a greater mean EBL of $578 \mathrm{~mL}(95 \%$

Table 4 Multiple linear and logistic regression models using EBL and need for additional interventions to manage postpartum blood loss, respectively, as the outcomes

\begin{tabular}{|c|c|c|c|c|c|c|}
\hline \multirow[t]{2}{*}{ Risk factors } & \multicolumn{3}{|c|}{$\begin{array}{l}\text { Multiple linear regression (outcome: EBL, } \\
\mathrm{mL} \text { ) }\end{array}$} & \multicolumn{3}{|c|}{$\begin{array}{l}\text { Multiple logistic regression (outcome: need for additional } \\
\text { interventions) }\end{array}$} \\
\hline & Coefficient & $95 \% \mathrm{CI}$ & $P$ value & $\mathrm{aOR}$ & $95 \% \mathrm{CI}$ & $P$ value \\
\hline Recovery interval (per $10 \mathrm{~min}$ ) & -10.3 & -18 to -3 & 0.009 & 0.997 & 0.959 to 1.036 & 0.87 \\
\hline Morbid obesity & 591.6 & 397 to 786 & $<0.001$ & 1.334 & 0.562 to 3.163 & 0.51 \\
\hline Preeclampsia & 96.9 & -212 to 406 & 0.54 & 0.829 & 0.174 to 3.952 & 0.81 \\
\hline Chorioamnionitis & 29.8 & -150 to 210 & 0.75 & 1.078 & 0.450 to 2.587 & 0.87 \\
\hline Macrosomia & 78.7 & -275 to 432 & 0.66 & 1.224 & 0.241 to 6.216 & 0.81 \\
\hline Multiple pregnancy & -144.8 & -595 to 305 & 0.53 & 1.237 & 0.141 to 0.872 & 0.85 \\
\hline Polyhydramnios & 306.4 & -149 to 762 & 0.19 & 0.995 & 0.110 to 9.005 & 1.00 \\
\hline Oxytocin induction & -26.2 & -137 to 85 & 0.64 & 1.288 & 0.764 to 2.173 & 0.34 \\
\hline $\begin{array}{l}\text { Oxytocin augmentation } \\
\text { (per } 100 \mathrm{mU} \text { ) }\end{array}$ & -0.41 & -1.14 to 0.32 & 0.27 & 1.004 & 1.001 to 1.008 & 0.005 \\
\hline
\end{tabular}

$\mathrm{aOR}=$ odds ratio adjusted for postpartum hemorrhage risk factors; $\mathrm{CI}=$ confidence interval; $\mathrm{EBL}=$ estimated blood loss 
CI, 342 to $815 ; P<0.001)$ than those who did not receive additional uterotonics. These patients also received a greater mean dose of oxytocin during labour augmentation by $3,505 \mathrm{mU}$ (95\% CI, 637 to 6,373; $P=0.02)$ and for a longer duration by $178 \mathrm{~min}(95 \%$ CI, 30 to $326 ; P=0.02$ ). No significant difference was noted in the recovery interval or BMI between the two groups.

\section{Discussion}

Our study showed that an increase in the oxytocin recovery interval is associated with a reduction in postpartum blood loss in parturients undergoing a CD for labour arrest following oxytocin augmented labour. Amongst the presumed risk factors for PPH, we found morbid obesity to be associated with an increase in blood loss at delivery. Moreover, the total amount and duration of oxytocin administered for labour augmentation were associated with the higher use of additional interventions to control postpartum bleeding.

At the study institution, oxytocin is typically discontinued after a CD is indicated for labour arrest. There is variability in the duration of the oxytocin-free period prior to the $\mathrm{CD}$ depending on the availability of an operating room and personnel and prioritization of cases. These conditions provided us with an opportunity to investigate the clinical implications of a varying oxytocinfree period following augmented labour. We included women who received oxytocin for labour augmentation for more than two hours to select those who received sufficient oxytocin to induce OTR desensitization. The length of this inclusion criterion was based on studies of pregnant human myometrium in vitro showing that two hours of exposure to oxytocin resulted in a substantial decline in subsequent oxytocin-induced contractions. ${ }^{10,14}$ We also based our parameter on a clinical study in which higher doses of oxytocin were required to achieve adequate uterine tone in women exposed to oxytocin. ${ }^{15}$ Clinically, OTR desensitization from augmented labour is associated with an increased risk of PPH depending on the dose and duration of oxytocin administered during labour. ${ }^{8-10,13,16,17,24}$ Although we did not observe more blood loss with increasing oxytocin administration during labour, an increased use of additional interventions suggests that there was poor uterine tone at delivery.

Various studies in the literature have described OTR desensitization $^{10-13}$; however, little is known about the potential implications of OTR resensitization. Cell-based studies have shown that OTR resensitization following oxytocin pretreatment occurs in a time-dependent manner following discontinuation of oxytocin. An oxytocin recovery interval of four hours markedly enhanced oxytocin-OTR binding as compared with a 45-min duration, ${ }^{25}$ while an increase in the interval from 5-15 min led to an increase in effective oxytocin responsiveness. $^{26}$ A more recent study found that increasing the recovery period from 30-90 $\mathrm{min}$ did not improve the contractile response to oxytocin in myometrial samples in vitro. ${ }^{27}$ The discrepancies between these results may be a consequence of differing cell types, culture conditions, and oxytocin pretreatment regimens. Furthermore, the recycling or synthesis of OTRs may depend, at least in part, on cell signals mediated by in vivo factors not reproduced in the in vitro studies. These issues highlight the difficulty of studying OTR resensitization in vitro and extrapolating results to the clinical setting.

Following OTR desensitization during labour augmentation, the oxytocin recovery interval in our study represented the anticipated time interval during which resensitization can occur. The time-dependent reduction in postpartum blood loss may have resulted from OTR resensitization, which restores the myometrial responsiveness to oxytocin administered for $\mathrm{PPH}$ prophylaxis. These clinical findings parallel the timedependent restoration of OTR responsiveness to subsequent oxytocin challenges following oxytocin pretreatment in in vitro studies. ${ }^{25,26}$

In addition to the oxytocin recovery interval, morbid obesity was associated with EBL. The role of obesity as a risk factor for $\mathrm{PPH}$ remains debated..$^{28-30}$ The contrasting results may be due to differences in the covariates, such as ethnicity, mode of delivery and oxytocin exposure in the statistical models, or the outcomes used to define PPH. We observed that the blood loss in morbidly obese women was about $600 \mathrm{~mL}$ greater than that in non-morbidly obese mothers; however, this was not associated with the need for more interventions to manage the blood loss. Interestingly, studies finding an association between $\mathrm{PPH}$ and obesity used blood loss ( $\geq 1,000 \mathrm{~mL}$ ) to define $\mathrm{PPH},{ }^{28,29}$ whereas the study with an opposing finding used $\mathrm{PPH}$ requiring blood transfusion as their outcome. ${ }^{30}$ Obese women have different signalling pathways modulating OTR function and ligand binding as well as alterations in OTR membrane viscosity and fluidity due to high cholesterol levels. Hence, they are likely to have impaired oxytocin-induced myometrial contractility, predisposing them to dysfunctional labour and $\mathrm{PPH} .^{31}$

Other PPH risk factors in our study were not found to be associated with the study outcomes. Prior studies examining the association of chorioamnionitis with $\mathrm{PPH}$ have been conflicting. ${ }^{8,17,32}$ We did not find an association despite the fact that our cases were confirmed by pathology reports. The lack of an association with some other previously identified risk factors may be the result of the 
low number of cases in our study with macrosomia, preeclampsia, multiple pregnancy, and polyhydramnios. Consideration of other factors contributing to blood loss is also needed. Patients who waited a shorter time for their CD may have been at higher risk of adverse obstetric outcomes that increase the likelihood of PPH. To this end, multivariable models and selection criteria were used.

There were some limitations to our study. For example, we cannot eliminate residual confounders completely, particularly those contributing to blood loss to a subclinical extent without any notable impact on $\mathrm{PPH}$ risk. These are not clearly defined in the literature but may convolute the association examined, since we measured the quantity of blood loss rather than the occurrence of $\mathrm{PPH}$. Nevertheless, we carefully controlled for PPH risk factors, including the use of oxytocin as a continuous variable to account for its contribution to blood loss more accurately. We excluded potential confounders such as early or late gestation, the use of general anesthesia, and uterine rupture. Hence, our multivariable model and selection criteria gave us the incentive to examine the association between oxytocin recovery interval and blood loss.

The hematocrit variation method to estimate blood loss was used because it provides more accurate results than visual estimations. Specifically, visual estimations have been shown to be subjective and dependent on the experience of the observer, and they tend to underestimate actual blood loss. ${ }^{21,33-35}$ Nevertheless, the hematocrit variation method is not without its limitations. It is possible that estimating blood loss using this method may lead to overestimation in morbidly obese women. Although it is known that indexed blood volume decreases in a non-linear manner with increasing body weight, ${ }^{36}$ it is unclear how this relates to the morbidly obese and pregnant population. Secondly, following the decrease in estrogen in the immediate postpartum period, there is diuresis of fluids accumulated during pregnancy and a relative elevation of the hematocrit. ${ }^{37}$ Since the EBL relies on the difference between pre- and post-CD hematocrit levels, a postpartum elevation in hematocrit from this physiologic phenomenon can artificially lower the EBL. Additional fluids can also alter patients' hematocrit level. A final limitation to our study is that, although the quantified reduction in blood loss was statistically significant, the clinical consequences of this blood loss were uncertain based on our secondary outcomes (i.e., little need for blood transfusion or additional uterotonics).

In summary, the study showed that an increase in the oxytocin recovery interval is associated with a reduction in postpartum blood loss. This suggests that, once a CD is considered for labour arrest, cessation of oxytocin for augmented labour may reduce the amount of postpartum blood loss. The extent of the reduction in blood loss found in this study likely does not warrant a mandatory recovery interval beyond what typically occurs. Nevertheless, particular attention must be given to morbidly obese women, as they are at a significantly higher risk of bleeding than non-obese parturients. Further investigations may be needed to assess the impact of the recovery interval on the need for additional interventions to manage blood loss as well as the implications of a recovery interval on patients at higher risk for $\mathrm{PPH}$, such as morbidly obese parturients.

Acknowledgements The authors gratefully acknowledge Kristi Downey (Perinatal Anesthesia Research Coordinator) for her assistance with preparing the database for data collection and creating the figures. We sincerely thank Eugene W. Yoon (Maternal-Infant Care Research Centre, Mount Sinai Hospital, Toronto) for performing the statistical analyses of the study.

Declaration of interests The authors have no conflicts of interest to disclose that may be relevant to the submitted work.

Editorial responsibility This submission was handled by Dr. Hilary P. Grocott, Editor-in-Chief, Canadian Journal of Anesthesia.

Author Contributions Gary Tran, Marcelo Kanczuk, and Mrinalini Balki were responsible for the study design and data analysis. Gary Tran and Marcelo Kanczuk were responsible for data acquisition. Gary Tran was responsible for maintaining the study records, writing the draft, and revising the manuscript. The author attests to the integrity of the original data and data analysis of the submitted work. Marcelo Kanczuk and Mrinalini Balki were responsible for manuscript preparation.

Funding Institutional funds. Mrinalini Balki was supported by Merit awards, Department of Anesthesia, University of Toronto, Canada.

\section{References}

1. Creanga AA, Berg CJ, Syverson C, Seed K, Bruce FC, Callaghan $W M$. Pregnancy-related mortality in the United States, 20062010. Obstet Gynecol 2015; 125: 5-12.

2. Khan KS, Wojdyla D, Say L, Gulmezoglu AM, Van Look PF. WHO analysis of causes of maternal death: a systematic review. Lancet 2006; 367: 1066-74.

3. Mehrabadi A, Liu S, Bartholomew S, et al. Temporal trends in postpartum hemorrhage and severe postpartum hemorrhage in Canada from 2003 to 2010. J Obstet Gynaecol Can 2014; 36: 2133.

4. Mehrabadi A, Hutcheon J, Lee L, Kramer M, Liston R, Joseph $K S$. Epidemiological investigation of a temporal increase in atonic postpartum haemorrhage: a population-based retrospective cohort study. BJOG 2013; 120: 853-62.

5. World Health Organization. WHO Recommendations for Augmentation of Labour. Geneva: WHO; 2014. Available from URL: http://apps.who.int/iris/bitstream/10665/112825/1/9789241 507363_eng.pdf (accessed February 2017).

6. Westhoff G, Cotter AM, Tolosa JE. Prophylactic oxytocin for the third stage of labour to prevent postpartum haemorrhage. Cochrane Database Syst Rev 2013; 10: CD001808.

7. World Health Organization. WHO Recommendations for the Prevention and Treatment of Postpartum Hemorrhage. Geneva: 
WHO; 2012. Available from URL: http://apps.who.int/iris/ bitstream/10665/75411/1/9789241548502_eng.pdf (accessed February 2017).

8. Grotegut CA, Paglia MJ, Johnson LN, Thames B, James AH. Oxytocin exposure during labor among women with postpartum hemorrhage secondary to uterine atony. Am J Obstet Gynecol 2011; 204: 56.e1-6.

9. Belghiti J, Kayem G, Dupont C, Rudigoz RC, Bouvier-Colle $M H$, Deneux-Tharaux $C$. Oxytocin during labour and risk of severe postpartum haemorrhage: a population-based, cohort-nested casecontrol study. BMJ Open 2011; 1: e000514.

10. Balki M, Erik-Soussi M, Kingdom J, Carvalho JC. Oxytocin pretreatment attenuates oxytocin-induced contractions in human myometrium in vitro. Anesthesiology 2013; 119: 552-61.

11. Phaneuf S, Asboth G, Carrasco MP, et al. Desensitization of oxytocin receptors in human myometrium. Hum Reprod Update 1998; 4: 625-33.

12. Phaneuf $S$, Rodriguez Linares B, TambyRaja RL, MacKenzie IZ, Lopez Bernal A. Loss of myometrial oxytocin receptors during oxytocin-induced and oxytocin-augmented labour. J Reprod Fertil 2000; 120: 91-7.

13. Robinson C, Schumann $R$, Zhang $P$, Young RC. Oxytocin-induced desensitization of the oxytocin receptor. Am J Obstet Gynecol 2003; 188: 497-502.

14. Balki M, Erik-Soussi M, Kingdom J, Carvalho JC. Comparative efficacy of uterotonic agents: in vitro contractions in isolated myometrial strips of labouring and non-labouring women. Can J Anesth 2014; 61: 808-18.

15. Nguyen-Lu N, Carvalho JC, Farine D, Seaward G, Ye XY, Balki $M$. Carbetocin at cesarean delivery for labour arrest: a sequential allocation trial to determine the effective dose. Can J Anesth 2015; 62: 866-74.

16. Waterstone $M$, Bewley $S$, Wolfe $C$. Incidence and predictors of severe obstetric morbidity: case-control study. BMJ 2001; 322: 1089-93; discussion 1093-4.

17. Combs CA, Murphy EL, Laros $R K J r$. Factors associated with postpartum hemorrhage with vaginal birth. Obstet Gynecol 1991; 77: 69-76.

18. Khan M, Balki M, Ahmed I, Farine D, Seaward G, Carvalho JC. Carbetocin at elective cesarean delivery: a sequential allocation trial to determine the minimum effective dose. Can J Anesth 2014; 61: 242-8.

19. El-Tahan MR, Warda OM, Yasseen AM, Attallah MM, Matter $M K$. A randomized study of the effects of preoperative ketorolac on general anaesthesia for caesarean section. Int J Obstet Anesth 2007; 16: 214-20.

20. Sheehan SR, Montgomery AA, Carey $M$, et al. Oxytocin bolus versus oxytocin bolus and infusion for control of blood loss at elective caesarean section: double blind, placebo controlled, randomised trial. BMJ 2011; 343: d4661.

21. Stafford I, Dildy GA, Clark SL, Belfort MA. Visually estimated and calculated blood loss in vaginal and cesarean delivery. Am J Obstet Gynecol 2008; 199: 519.e1-7.

22. Mallappa Saroja CS, Nankani A, El-Hamamy E. Uterine compression sutures, an update: review of efficacy, safety and complications of B-Lynch suture and other uterine compression techniques for postpartum haemorrhage. Arch Gynecol Obstet 2010; 281: 581-8.

23. Bakri YN, Amri A, Abdul Jabbar F. Tamponade-balloon for obstetrical bleeding. Int J Gynaecol Obstet 2001; 74: 139-42.

24. Harris RJ. A Primer of Multivariate Statistics. 2nd ed. New York: Academic Press Inc.; 1985.

25. Conti F, Sertic S, Reversi A, Chini B. Intracellular trafficking of the human oxytocin receptor: evidence of receptor recycling via a Rab4/Rab5 "short cycle". Am J Physiol Endocrinol Metab 2009; 296: E532-42.

26. Willets JM, Brighton PJ, Mistry R, Morris GE, Konje JC, Challiss $R A$. Regulation of oxytocin receptor responsiveness by $\mathrm{G}$ protein-coupled receptor kinase 6 in human myometrial smooth muscle. Mol Endocrinol 2009; 23: 1272-80.

27. Balki M, Ramachandran N, Lee $S$, Talati $C$. The recovery time of myometrial responsiveness after oxytocin-induced desensitization in human myometrium in vitro. Anesth Analg 2016; 122: 1508-15.

28. Blomberg $M$. Maternal obesity and risk of postpartum hemorrhage. Obstet Gynecol 2011; 118: 561-8.

29. Fyfe EM, Thompson JM, Anderson NH, Groom KM, McCowan $L M$. Maternal obesity and postpartum haemorrhage after vaginal and caesarean delivery among nulliparous women at term: a retrospective cohort study. BMC Pregnancy Childbirth 2012; 12: 12.

30. Paglia MJ, Grotegut CA, Johnson LN, Thames B, James AH. Body mass index and severe postpartum hemorrhage. Gynecol Obstet Invest 2012; 73: 70-4.

31. Zhang J, Bricker L, Wray S, Quenby S. Poor uterine contractility in obese women. BJOG 2007; 114: 343-8.

32. Wetta LA, Szychowski JM, Seals S, Mancuso MS, Biggio JR' Tita $A T$. Risk factors for uterine atony/postpartum hemorrhage requiring treatment after vaginal delivery. Am J Obstet Gynecol 2013; 209: 51.e1-6.

33. Dildy GA 3rd, Paine AR, George NC, Velasco C. Estimating blood loss: can teaching significantly improve visual estimation? Obstet Gynecol 2004; 104: 601-6.

34. Sukprasert $M$, Choktanasiri W, Ayudhya NI, Promsonthi $P, O$ Prasertsawat $P$. Increase accuracy of visual estimation of blood loss from education programme. J Med Assoc Thail 2006; 89 Suppl 4: S54-9.

35. Zhang WH, Deneux-Tharaux C, Brocklehurst P, Juszczak E, Joslin M. Alexander S; EUPHRATES Group. Effect of a collector bag for measurement of postpartum blood loss after vaginal delivery: cluster randomised trial in 13 European countries. BMJ 2010; 340: c293.

36. Lemmens HJ, Bernstein DP, Brodsky JB. Estimating blood volume in obese and morbidly obese patients. Obes Surg 2006; 16: 773-6.

37. Gharoro EP, Enabudoso EJ. Relationship between visually estimated blood loss at delivery and postpartum change in haematocrit. J Obstet Gynaecol 2009; 29: 517-20. 